\title{
Conversion of deoxynivalenol to 3- acetyldeoxynivalenol in barley-derived fuel ethanol co-products with yeast expressing trichothecene 3-O-acetyltransferases
}

\author{
Piyum A Khatibi', Justin Montanti ${ }^{3}$, Nhuan P Nghiem³ ${ }^{3}$ Kevin B Hicks ${ }^{3}$, Greg Berger ${ }^{2}$, Wynse S Brooks², \\ Carl A Griffey ${ }^{2}$ and David G Schmale \|\|$^{1^{*}}$
}

\begin{abstract}
Background: The trichothecene mycotoxin deoxynivalenol (DON) may be concentrated in distillers dried grains with solubles (DDGS; a co-product of fuel ethanol fermentation) when grain containing DON is used to produce fuel ethanol. Even low levels of DON ( $\leq 5 \mathrm{ppm}$ ) in DDGS sold as feed pose a significant threat to the health of monogastric animals. New and improved strategies to reduce DON in DDGS need to be developed and implemented to address this problem. Enzymes known as trichothecene 3-O-acetyltransferases convert DON to 3acetyldeoxynivalenol (3ADON), and may reduce its toxicity in plants and animals.

Results: Two Fusarium trichothecene 3-O-acetyltransferases (FgTRI101 and FfTRI201) were cloned and expressed in yeast (Saccharomyces cerevisiae) during a series of small-scale ethanol fermentations using barley (Hordeum vulgare). DON was concentrated 1.6 to 8.2 times in DDGS compared with the starting ground grain. During the fermentation process, FgTRI101 converted $9.2 \%$ to $55.3 \%$ of the DON to 3ADON, resulting in DDGS with reductions in DON and increases in 3ADON in the Virginia winter barley cultivars Eve, Thoroughbred and Price, and the experimental line $\mathrm{VA06H}-25$. Analysis of barley mashes prepared from the barley line VA04B-125 showed that yeast expressing FfTRI201 were more effective at acetylating DON than those expressing FgTRI101; DON conversion for FfTRI201 ranged from $26.1 \%$ to $28.3 \%$, whereas DON conversion for FgTRI101 ranged from $18.3 \%$ to $21.8 \%$ in VA04B-125 mashes. Ethanol yields were highest with the industrial yeast strain Ethanol Red ${ }^{\circledR}$, which also consumed galactose when present in the mash.
\end{abstract}

Conclusions: This study demonstrates the potential of using yeast expressing a trichothecene 3-O-acetyltransferase to modify DON during commercial fuel ethanol fermentation.

\section{Background}

As the USA attempts to decrease its reliance on fossil fuels, alternative fuel sources are in high demand. Barley is an emerging alternative to corn as an important source for fuel ethanol [1]. Winter barley may be grown during the winter months, supplying an additional crop on land that would otherwise be fallow [2]. This would provide additional income for farmers, and an ethanol feedstock that does not compete with feed and food

\footnotetext{
* Correspondence: dschmale@vt.edu

'Virginia Tech, Department of Plant Pathology, Physiology and Weed

Science, Blacksburg, VA 24061, Virginia Tech, USA

Full list of author information is available at the end of the article
}

markets. In Virginia, new cultivars of barley with high starch content are being developed to support fuel ethanol production [3]. The USDA Agricultural Research Service predicts that North America will be able to produce up to 2 billion gallons of ethanol per year from barley alone $[4,5]$.

A valuable co-product of fuel ethanol production, known as distillers dried grains with solubles (DDGS), is increasingly being used as a feed source for domestic animals [6]. DDGS contains high levels of protein, fiber, minerals and vitamins $[7,8]$. An increase in the supply and demand for DDGS [9] is expected to coincide with the increased production of fuel ethanol in commercial

\section{C) Biomed Central}


plants [10], which rely on the sale of DDGS to turn a profit [11].

One of the challenges facing the fuel ethanol industry is the management of mycotoxins such as deoxynivalenol (DON) in DDGS. Barley can become contaminated with DON in the field after infection with the fungal plant pathogen Fusarium graminearum (teleomorph Gibberella zeae). Barley contaminated with high levels of DON is excluded from feeds and foods [12]. DON is a potent inhibitor of protein synthesis [13], and animals ingesting DON may show symptoms of vomiting and feed refusal [14].

Enzymes known as trichothecene 3-O-acetyltransferases have the ability to modify DON by converting it to an acetylated derivative [15]. These enzymes are also produced by fungi in the genus Fusarium, and are encoded by the genes TRI101 or TRI201 [16,17]. The enzymatic modification involves the attachment of an acetyl group to the $\mathrm{C}-3$ hydroxyl moiety of the trichothecene molecule [15], forming the derivative 3-acetyldeoxynivalenol (3ADON) [18]. Expression of TRI101 has been shown to reduce the phytotoxic effects of trichothecenes in tobacco and rice $[19,20]$, and to decrease the inhibitory effects of trichothecenes on the growth of Saccharomyces pombe [18] and Chlamydomonas reinnardtii [21]. In vitro assays have shown DON to be more inhibitive than $3 \mathrm{ADON}$ of protein translation in rabbit reticulocytes [18], of DNA synthesis in mouse 3T3 fibroblasts [22] and of proliferation of murine lymphocytes [23]. However, 3ADON was only 1.4 times less toxic than DON in mice based on $50 \%$ lethal dose $\left(\mathrm{LD}_{50}\right)$ values $[24,25]$. Although the difference in toxicity between DON and 3ADON in vivo is small, toxicology data in animals are limited [26], and to our knowledge, no alternative DON modification strategies with the potential to reduce toxicity are currently available.

Recently, seven trichothecene 3-O-acetyltransferases were evaluated for their ability to modify the mycotoxin DON [17]. In this study, we tested the hypothesis that two of these enzymes (FgTRI101 and FfTRI201) would reduce DON in DDGS resulting from a series of smallscale barley ethanol fermentations. To our knowledge, this is the first detailed report of yeast expressing a DON modification enzyme during barley ethanol fermentation, and provides a basis for evaluating novel detoxification enzymes such as DON de-epoxide hydrolases to reduce DON in DDGS [22,27].

\section{Methods}

Yeasts, enzymes and barley genotypes

Yeast strains

We used two yeast strains in this study: a commercial alcohol yeast (Dry Ethanol $\operatorname{Red}^{\circledR}$; Fermentis, Marcq-en-
Baroeul, France), which was used as a representative yeast strain for industrial ethanol production, and the $S$. cerevisiae strain RW2802 (PDR5 leu2 ura3-52 met5; kindly provided by Dr J. Golin, The Catholic University, Washington, DC, USA). RW2802 was used either as untransformed (control) or transformed with FgTRI101 or FfTRI201, as described below. The media used for culturing wild-type and transformed RW2802 have been described previously [17].

\section{Acetyltransferases}

Gene isolation, cloning and expression of FgTRI101, FfTRI201 and FsTRI12 (a trichothecene efflux pump) were conducted as described previously [17]. The two vectors transformed into RW2802 for fermentation assays (Figure 1) were created using SeqBuilder (Lasergene version 8.1.1; DNAStar, Madison, WI, USA). Plasmid pTRI101YES contained either the FgTRI101 or the FfTRI201 gene (Figure 1). The pTRI12ESC vector was derived from pESC-LEU, and contained the F. sporotrichioides TRI12 gene (FsTRI12) (Figure 1).

\section{Barley cultivars and experimental lines}

In this study, we used both hulled and hulless winter barley: the hulled cultivars Price and Thoroughbred and the experimental hulled barley line VA04B-125, plus the hulless cultivar Eve and the experimental hulless line VA06H-25. These five types of barley were planted in a randomized complete block in mist-irrigated nurseries (Mt Holly, VA, USA). Plots $1.5 \mathrm{~m} \times$ $13.4 \mathrm{~m}$ in size were used to produce sufficient material for analysis of DON concentrations in barley grain, barley mash and DDGS. Corn (Zea mays) kernels colonized with Virginia strains of $F$. graminearum were applied to plots at the boot stage of growth to encourage infection and DON contamination in the harvested grain. Grain was harvested in summer 2010 using a small research plot combine.

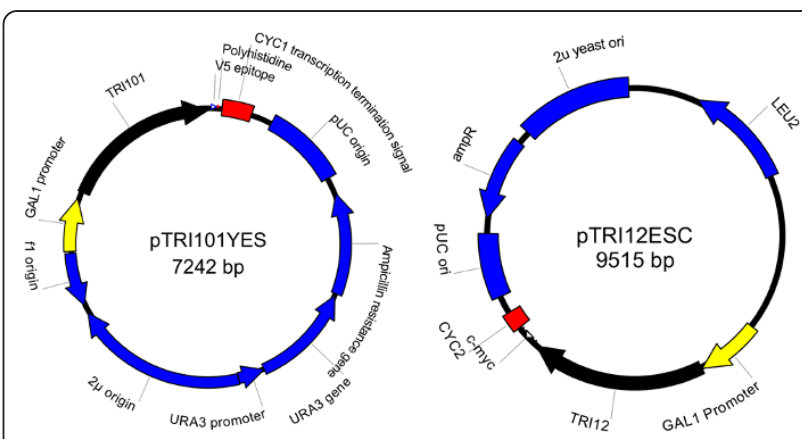

Figure 1 Two vectors transformed into yeast strain RW2802 for barley fermentation assays. (Left) The plasmid pTRI101YES contains either the FgTRI101 or FfTRI201 gene; (right) he pTRI12ESC vector is derived from pESC-LEU, and contains the Fusarium sporotrichioides TRl12 gene. 


\section{Preparation and fermentation of the barley mashes Eve, Price, Thoroughbred and VAO6H-25}

The following method for making barley mash was based on the enhanced dry grind enzymatic (EDGE) process developed by Nghiem et al. [28], and was used for all of the genotypes (preparation of the mash for VA04B-125 had some modifications, described later). Small samples of barley kernels (2000 g) were cleaned using a dockage tester (Carter Day International, Minneapolis, MN, USA) and ground to a particle size of 1 mm (Model 1 Wiley mill; Thomas Scientific, Swedesboro, NJ, USA). Two mashes of $1250 \mathrm{~g}$ were prepared, each containing $20 \% \mathrm{w} / \mathrm{w}$ dry solids. Deionized (DI) water (mash 1) or $10 \% \mathrm{w} / \mathrm{w}$ galactose solution (mash 2 ) was added to the ground grain to reach a final mass of $1250 \mathrm{~g}$, and the $\mathrm{pH}$ was adjusted to 5.2 with $5 \mathrm{~mol} / \mathrm{l} \mathrm{sul-}$ furic acid. Two enzymes, a $\beta$-glucanase (OPTIMASH BG; Genencor, Palo Alto, CA, USA) and an $\alpha$-amylase (SPEZYME XTRA; Genencor) were then added at 29.6 $\mu \mathrm{l}(0.13 \mathrm{~kg} /$ ton dry solids $)$ and $68.2 \mu \mathrm{l}(0.30 \mathrm{~kg} /$ ton dry solids), respectively. Liquefaction was carried out at $90^{\circ}$ $\mathrm{C}$ for 2 hours in an oil bath with mechanical stirring. During liquefaction, small volumes of DI water were added to compensate for water loss due to evaporation. After 2 hours, the mash was cooled in an ice-water bath to a temperature of $32^{\circ} \mathrm{C}$. Once cooled, the mass of the mash was adjusted with DI water back to $1250 \mathrm{~g}$. The $\mathrm{pH}$ was then adjusted to 4.5 with $5 \mathrm{~mol} / \mathrm{l}$ sulfuric acid. A glucoamylase/protease mix (FERMENZYME L-400; Genencor) and a developmental $\beta$-glucosidase (Genencor) were added at $147.7 \mu \mathrm{l}(0.65 \mathrm{~kg} /$ ton dry solids $)$ and $138.6 \mu \mathrm{l}(0.61 \mathrm{~kg} /$ ton dry solids), respectively. To provide a nitrogen source, $0.5 \mathrm{~g}$ of urea was added to achieve a final concentration of $400 \mathrm{mg} / \mathrm{l}$.

Fermentation was then carried out in $250 \mathrm{ml}$ shake flasks containing $100 \mathrm{~g}$ each of the appropriate mash. Of the nine flasks, three were designated for each strain of yeast: Dry Ethanol Red, RW2802, and RW2802 transformed with FgTRI101/FsTRI12. Each flask was inoculated with the appropriate yeast strain, and placed in a shaking incubator set at a speed of $200 \mathrm{rpm}$ and a temperature of $30^{\circ} \mathrm{C}$ for 66 hours. The Dry Ethanol Red yeast was rehydrated in DI water at $5 \% \mathrm{w} / \mathrm{w}$, and 0.75 $\mathrm{ml}$ of this slurry was added to each designated flask. For the untransformed and transformed yeast strain RW2802 inocula, $100 \mathrm{ml}$ liquid cultures were grown for two days at $30^{\circ} \mathrm{C}$ in a shaking incubator set at $200 \mathrm{rpm}$. Cultures of RW2802 and the transformed yeast cells were then separated by centrifugation at $1500 \mathrm{~g}$ for 5 minutes. The supernatants were discarded, and the cell pellets were resuspended in $2 \mathrm{ml}$ of DI water (final optical density at $600 \mathrm{~nm}\left(\mathrm{OD}_{600}\right)$ was approximately 15.2). A $1.0 \mathrm{ml}$ aliquot of the appropriate liquid culture was added to each designated flask.

\section{VA04B-125 mashes}

In a separate experiment to test the acetylation levels of two different acetyltransferases (FgTRI101 and FfTRI201), we used ground grain from hulled barley line VA04B-125. Mashes of the VA04B-125 hulled barley line were prepared using the same procedure described above for the other four types of barley, with the following modifications. Two $1500 \mathrm{~g}$ mashes were prepared. $\beta$-glucanase and $\alpha$-amylase were added at $35.5 \mu \mathrm{l}(0.13$ $\mathrm{kg} /$ ton dry solids) and $81.8 \mu \mathrm{l}(0.30 \mathrm{~kg} /$ ton dry solids $)$, respectively. The glucoamylase/protease mix and $\beta$-glucosidase were added at $177.4 \mu \mathrm{l}(0.65 \mathrm{~kg} /$ ton dry solids $)$ and $166.4 \mu \mathrm{l}(0.61 \mathrm{~kg} /$ ton dry solids), respectively, then $0.6 \mathrm{~g}$ urea was added. Twelve small-scale fermentations were performed, of which three were designated for each of the four yeast strains. These included Dry Ethanol Red, untransformed RW2802, RW2802 transformed with FgTRI101/FsTRI12 and RW2802 transformed with FfTRI201/FsTRI12. Fermentations were carried out for 71 hours. Cultures of untransformed and transformed yeast strain RW2802 were separated by centrifugation. The supernatants were discarded, and the cell pellets were resuspended in $3 \mathrm{ml}$ of DI water $\left(\mathrm{OD}_{600}\right.$ approximately 7.0). A $1.0 \mathrm{ml}$ aliquot of liquid culture was added to each designated flask. A summary of the experiments described in this section is provided in Table 1.

\section{Extraction of trichothecene mycotoxins from ground barley grain, barley mash and distillers dried grains with solubles}

Grains from all five barley genotypes (VA06H-25, VA04B-125, Thoroughbred, Price and Eve) were ground in a mill as described above, and mycotoxin extractions were performed on $1 \mathrm{~g}$ subsamples. Each subsample was combined with $8 \mathrm{ml}$ of extraction solvent $(86 \% \mathrm{v} / \mathrm{v}$ acetonitrile in DI water) in a capped polypropylene tube, and placed on a shaker at $200 \mathrm{rpm}$ for 1 hour at room temperature (approximately $25^{\circ} \mathrm{C}$ ). DON was detected and quantified using gas chromatography/mass spectrometry (GC/MS) (see below).

For the fermentation mashes, subsamples of $1 \mathrm{~mL}$ (weighing about $1 \mathrm{~g}$ ) were taken at $0,20,44$ and 66 hours, except in the case of VA04B-125, for which samples were taken at 0, 23, 47 and 71 hours. Each mash subsample was added to $7 \mathrm{ml}$ of extraction solvent (described above). The mash sample/solvent mixtures were placed on a shaker at $200 \mathrm{rpm}$ for 1 hour at room temperature.

At the end of fermentation, the entire contents of the experimental flasks were transferred into aluminum weighing pans, and dried in an oven at $55^{\circ} \mathrm{C}$ for 4 days. The collected DDGS was ground in a coffee grinder (Hamilton Beach, Model 80365, Southern Pines, NC, USA) positioned at the 'espresso' and ' 12 cup' setting. 
Table 1 Combination of Virginia barley line/cultivar, yeast strain and treatment for each mash ${ }^{1}$ prepared for deoxynivalenol (DON) modification

\begin{tabular}{|c|c|c|c|}
\hline Barley line/cultivar & Yeast strain & Flasks, $\mathrm{n}$ & Treatment \\
\hline \multirow[t]{6}{*}{ VA06H-252 } & Dry Ethanol Red & 3 & No galactose \\
\hline & RW2802 & 3 & No galactose \\
\hline & RW2802 FgTRI101/FsTRI12 & 3 & No galactose \\
\hline & Dry Ethanol Red & 3 & Galactose \\
\hline & RW2802 & 3 & Galactose \\
\hline & RW2802 FgTRI101/FsTRI12 & 3 & Galactose \\
\hline \multirow[t]{8}{*}{ VA04B- $125^{3}$} & Dry Ethanol Red & 3 & No galactose \\
\hline & RW2802 & 3 & No galactose \\
\hline & RW2802 FgTRI101/FsTRI12 & 3 & No galactose \\
\hline & RW2802 FfTRI201/FsTRI12 & 3 & No galactose \\
\hline & Dry Ethanol Red & 3 & Galactose \\
\hline & RW2802 & 3 & Galactose \\
\hline & RW2802 FgTRI101/FsTRI12 & 3 & Galactose \\
\hline & RW2802 FfTRI201/FsTRI12 & 3 & Galactose \\
\hline \multirow[t]{6}{*}{ Thoroughbred $^{3}$} & Dry Ethanol Red & 3 & No galactose \\
\hline & RW2802 & 3 & No galactose \\
\hline & $\underline{\text { RW2802 FgTRI101/FsTRI12 }}$ & 3 & No galactose \\
\hline & Dry Ethanol Red & 3 & Galactose \\
\hline & RW2802 & 3 & Galactose \\
\hline & RW2802 FgTRI101/FsTRI12 & 3 & Galactose \\
\hline \multirow[t]{6}{*}{ Price $^{3}$} & Dry Ethanol Red & 3 & No galactose \\
\hline & RW2802 & 3 & No galactose \\
\hline & RW2802 FgTRI101/FsTRI12 & 3 & No galactose \\
\hline & Dry Ethanol Red & 3 & Galactose \\
\hline & RW2802 & 3 & Galactose \\
\hline & RW2802 FgTRI101/FsTRI12 & 3 & Galactose \\
\hline \multirow[t]{6}{*}{$\overline{\mathrm{Eve}^{2}}$} & Dry Ethanol Red & 3 & No galactose \\
\hline & RW2802 & 3 & No galactose \\
\hline & RW2802 FgTRI101/FsTRI12 & 3 & No galactose \\
\hline & Dry Ethanol Red & 3 & Galactose \\
\hline & RW2802 & 3 & Galactose \\
\hline & RW2802 FgTRI101/FsTRI12 & 3 & Galactose \\
\hline
\end{tabular}

\footnotetext{
${ }^{1}$ For each barley genotype, three replicate mashes were prepared for each yeast strain, to give a total of 96 mashes. Mashes were prepared using either deionized water or $10 \% \mathrm{w} / \mathrm{w}$ galactose solution.

${ }^{2}$ Hulless genotype.

${ }^{3}$ Hulled genotype.
}

The ground DDGS samples weighing $1 \mathrm{~g}$ were added to $8 \mathrm{ml}$ of extraction solvent and shaken at $200 \mathrm{rpm}$ for 1 hour at room temperature. The mass of DON and $3 \mathrm{ADON}$ in each DDGS sample was determined by multiplying the concentration ( $\mathrm{ppm}$ ) by the mass of each corresponding DDGS sample.

Extraction solvents from the mash and DDGS, containing trichothecene mycotoxins, were passed through a clean-up column composed of a $1 \mathrm{~g}$ mixture of $\mathrm{C} 18$ (VWR, Radnor, PA, USA) and aluminum oxide (SigmaAldrich, St. Louis, MO, USA) at a 1:3 ratio. A $2 \mathrm{ml}$ aliquot of eluent was transferred to a glass test tube, and evaporated to dryness using a nitrogen evaporator set at $55^{\circ} \mathrm{C}$, then $100 \mu \mathrm{l}$ of the derivatization agent n-trimethylsilylimidazole (TMSI; Sigma-Aldrich, St. Louis, MO, USA) was added to the dried samples. After 30 minutes, $500 \mu \mathrm{l}$ of isooctane containing $5 \mathrm{ppm}$ of the chlorinated hydrocarbon mirex (Sigma-Aldrich, St. Louis, MO, USA) was added to each tube, followed by $500 \mu \mathrm{l}$ of water to quench the reaction. Samples were mixed by vortex for 10 seconds, and $150 \mu \mathrm{l}$ of the isooctane/mirex supernatant was removed and transferred to chromatography vials for GC/MS analysis. The GC/MS detected and quantified DON and 3ADON in ppm. The percentage DON conversion (DON to $3 \mathrm{ADON}$ ) was determined by calculating the percentage of $3 \mathrm{ADON}$ 
concentration in relation to total toxin in the subsample $(\mathrm{DON}+3 \mathrm{ADON})$. The concentration of DON and $3 \mathrm{ADON}$ and the percentage conversion values are reported as means \pm standard error of the mean (SEM).

\section{Gas chromatography/mass spectrophotometry analysis} GC/MS analysis was conducted using a GC/MS system (6890/5975; Agilent Technologies, Santa Clara, CA, USA) operating in selected ion monitoring (SIM) mode as described previously [17]. Mirex was used as an internal control at $0.5 \mathrm{ppm}$. SIM mode detected DON and $3 \mathrm{ADON}$ target ions at a mass:charge ratio of 512 and 392 respectively, with reference ions at 422 and 497 for DON and a reference ion at 467 for $3 A D O N$. SIM mode detected mirex target ions at a mass:charge ratio of 272 with reference ions at 276 and 237. DON and $3 \mathrm{ADON}$ were quantified in the samples using a quadratic regression model using pure DON and 3ADON standards (Biopure, Tulin, Austria) at concentrations of 0.5, 1.0, 5, 10 and $30 \mathrm{ppm}$.

\section{Protein extraction from VA04B-125 mashes}

Protein extraction for the barley-mash subsamples was conducted based on the method of Kushnirov [29] for western blot analysis. A subsample of $1 \mathrm{~g}$ was taken at the end of fermentation (71 hours) from mashes containing 1) transformed RW2802 expressing FgTRI101, 2) transformed RW2802 expressing FfTRI201, and 3) untransformed RW2802. Subsamples were separated by centrifugation at $1500 \mathrm{~g}$ for $5 \mathrm{~min}$. The supernatant was removed, and the mash pellet was resuspended in a mixture of $500 \mu \mathrm{l}$ DI water and $500 \mu \mathrm{l}$ of $0.2 \mathrm{~mol} / \mathrm{l}$ $\mathrm{NaOH}$, and held at room temperature for 5 minutes. After incubation at room temperature, the yeast cells were recovered by centrifugation, resuspended in $250 \mu \mathrm{l}$ of SDS sample buffer [29], and boiled for 3 minutes. Samples $(4 \mu \mathrm{l})$ of supernatant were loaded onto a $12 \%$ acrylamide SDS-PAGE gel, and run at $150 \mathrm{~V}$ for 1 hour, with a standard (Precision Plus Protein Dual Color; BioRad, Hercules, CA, USA) used to determine protein size. After separation, protein transfer to a nitrocellulose membrane (Bio-Rad) was conducted in a transfer chamber at $34 \mathrm{~mA}$ for 1 hour at room temperature. The transfer buffer was composed of $25 \mathrm{mmol} / \mathrm{l}$ Tris, 190 $\mathrm{mmol} / \mathrm{l}$ glycine, $2 \%$ SDS and 20\% liquid chromatography-MS-grade methanol. The membrane was then blocked in $7 \%$ nonfat dry milk in Tris-buffered saline with Tween (TBST; $10 \mathrm{mmol} / \mathrm{l}$ Tris $\mathrm{pH} 8,150 \mathrm{mmol} / \mathrm{l}$ $\mathrm{NaCl}, 0.05 \%$ Tween 20) for 1 hour at room temperature. The membrane was incubated with rabbit anti-FsTri101 primary antibody for 1 hour in $7 \%$ milk-TBST $(1: 5,000)$. After incubation with the primary antibody, the membrane was washed three times with $7 \%$ milk-TBST for 15 minutes each time. The membrane was incubated with the secondary antibody (alkaline phosphatase-conjugated anti-rabbit) for 1 hour in 7\% milk-TBST solution $(1: 10,000)$. The membrane was washed in TBST three times for $15 \mathrm{~min}$ each time, and then washed in TBS (without Tween 20) once for 15 minutes. The membrane was incubated for 3 minutes with the substrate (Lumi-Phos WB; Fisher Scientific, Pittsburgh, PA, USA) at a volume of $0.125 \mathrm{ml}$ for every $\mathrm{cm}^{2}$ of membrane. X-ray film was exposed to the membrane for 5 minutes and developed. FgTRI101 and FfTRI201 were purified from Escherichia coli as described previously, [17] and were used as reference controls for the western blot.

\section{Ethanol and sugar quantification}

For each subsample of mash taken during the time course study, the concentrations of ethanol, glucose and galactose were measured using an HPLC system (1200 Series; Agilent) equipped with a refractive index detector and a column (Aminex HPX-87H; Bio-Rad) with a guard column operating at $65^{\circ} \mathrm{C}$. The mobile phase was $5 \mathrm{mmol} / \mathrm{l} \mathrm{H}_{2} \mathrm{SO}_{4}$ pumped at a flow rate of $0.6 \mathrm{ml} / \mathrm{min}$. An additional $1 \mathrm{ml}$ mash sample was removed and separated by centrifugation at 12,000 rpm for 5 minutes. The supernatants were passed through a $0.2 \mu \mathrm{m}$ filter (TITAN; Fisher Scientific, Pittsburg, PA, USA), and stored in the freezer until HPLC analysis.

Theoretical ethanol yields based on the total starch plus $\beta$-glucans were calculated as described previously [28]. In experiments using Dry Ethanol Red yeast and $10 \% \mathrm{w} / \mathrm{w}$ galactose solution for mashing, galactose was also included in the total available fermentable substrates because the yeast strain used was also capable of metabolizing this sugar.

\section{Composition of distillers dried grains with solubles}

Compositional analysis of DDGS samples were conducted as described previously [28].

\section{Statistical analyses}

All comparisons were performed using the statistical program JMP (version 9.0.0; SAS Institute Inc., Cary, NC, USA). To measure significant differences, analyses of variance (ANOVA) were performed. If a significant difference $(P<0.05)$ was found with ANOVA, then Tukey-Kramer's honestly significant difference (HSD) post hoc test was performed.

\section{Results}

Data were analyzed from 96 small-scale barley-fermentation mashes prepared from five barley genotypes (VA06H-25, VA04B-125, Thoroughbred, Price and Eve). DON levels (mean \pm SEM) in the ground grain were $129.5 \pm 14.0,118.3 \pm 10.4,26.7 \pm 1.3,17.7 \pm 0.5$ and 2.8 
$\pm 0.3 \mathrm{ppm}$, respectively (Figure 2 ). Two mashes, one with galactose and one without galactose, were prepared for each barley crop using ground grain (Table 1).

\section{Deoxynivalenol/3-acetyldeoxynivalenol concentrations in barley mashes with galactose}

Addition of galactose induced FgTRI101/FsTRI12 or FfTRI201/FsTRI12 expression in the transformed yeast strain RW2802. Upon preparation of the mash $(0$ hours), DON levels in the dry grain were diluted with the addition of $10 \%$ galactose solution (Figure 2). At 0 hours of fermentation (no yeast), DON levels were 52.1 $\pm 1.5 \mathrm{ppm}$ (VA06H-25), $28.5 \pm 1.4 \mathrm{ppm}(\mathrm{VA} 04 \mathrm{~B}-125)$, $17.7 \pm 2.3 \mathrm{ppm}$ (Thoroughbred), $12.5 \pm 0.5 \mathrm{ppm}$ (Price) and $2.3 \pm 0.1 \mathrm{ppm}$ (Eve) (Figure 2). At the end of the fermentation, DON concentrations were reduced in all mashes containing transformed yeast, but were significantly reduced only in the VA06H-25 mashes $(P<0.01)$ (Figure 3). The concentration of DON in VA06H-25 after 66 hours of fermentation was $15.3 \pm 1.6 \mathrm{ppm}$ (transformed RW2802), $56.8 \pm 1.3 \mathrm{ppm}$ (untransformed RW2802) and $47.8 \pm 1.0 \mathrm{ppm}$ (Ethanol Red) (Figure 3). The concentration of 3ADON in VA06H-25 after 66 hours of fermentation was $18.8 \pm 0.7,2.8 \pm 0.1$ and 2.5 $\pm 0.0 \mathrm{ppm}$ for transformed RW2802, untransformed RW2802 and Ethanol Red, respectively (Figure 3).

\section{Percentage deoxynivalenol conversion in Eve, Price,} Thoroughbred and VA06H-25 mashes

Mash subsamples were collected over a period of 66 hours from all mashes containing galactose. Subsamples were taken at $0,20,44$ and 66 hours. In 20 hours, mean conversion levels ranged from $4.7 \pm 0.4 \%$ (Thoroughbred) to $28.9 \pm 1.0 \%$ (VA06H-25). At 44 hours, the mean conversion ranged from $8.0 \pm 0.5 \%$ (Eve) to 55.0 $\pm 1.2 \%$ (VA06H-25) for mashes with transformed yeast.

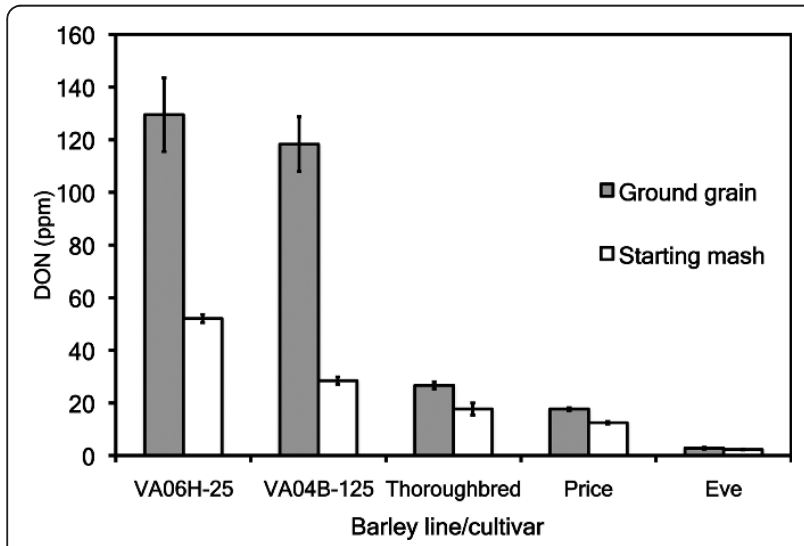

Figure 2 Deoxynivalenol (DON) concentrations in ground grain and starting (0 hours) mash (with galactose). DON was diluted upon creation of the mash by 1.2 to 4.2 times.

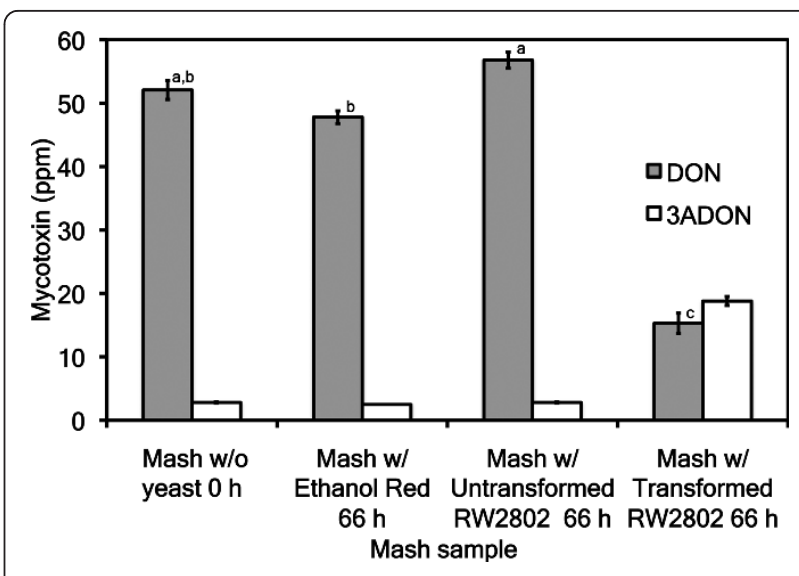

Figure 3 Deoxynivalenol (DON) and 3-acetyldeoxynivalenol (3ADON) concentrations for VA06H-25 hulless barley in fermentations containing galactose. Bars not connected by the same letter are significantly different. The concentration of DON in the mash with transformed RW2802 was significantly lower than both the starting mash without yeast and the mashes containing Ethanol Red and untransformed RW2802 yeast $(P<0.05)$.

The end of fermentation with transformed yeast yielded mean conversions ranging from $9.2 \pm 0.7 \%$ (Eve) to 55.3 $\pm 1.8 \%$ (VA06H-25). For each time point after 0 hours, mashes with transformed yeast had significantly higher conversion values than those with untransformed yeast strains $(P<0.05$ for pairwise comparisons conducted within each barley crop) (Figure 4). For untransformed yeast strains, the highest conversion at the end of the assay was $5.7 \pm 0.1 \%$ (Price, 66 hours) (Figure 4).

\section{Percentage deoxynivalenol conversion in VA04B-125 mashes}

In a separate experiment, the acetylation levels of two different acetyltransferases (FgTRI101 and FfTRI201) were compared using ground grain from the hulled barley line VA04B-125. Subsamples were collected at 0, 23, 47 and 71 hours. In VA04B-125 mashes, FfTRI201 produced a greater reduction in DON and an increased conversion of DON to $3 \mathrm{ADON}$ compared with FgTRI101 (Figure 4). DON conversion levels at the end of the assay for mashes with Ethanol Red and untransformed RW2802 were $10.6 \pm 0.9 \%$ and $9.6 \pm 0.4 \%$, respectively, whereas RW2802 expressing FgTRI101 or FfTRI201 had levels of $19.9 \pm 1.0 \%$ and $26.9 \pm 0.7 \%$, respectively (Figure 4).

Protein extractions were conducted on mashes to reveal the levels of FgTRI101 and FfTRI201. Western blot analysis detected the presence of FfTRI201 protein in all three mashes with FfTRI201-transformed RW2802 (Figure 5). No protein was detected in untransformed RW2802 mashes (Figure 5). Protein extractions conducted on mashes with FgTRI101-transformed yeast did 


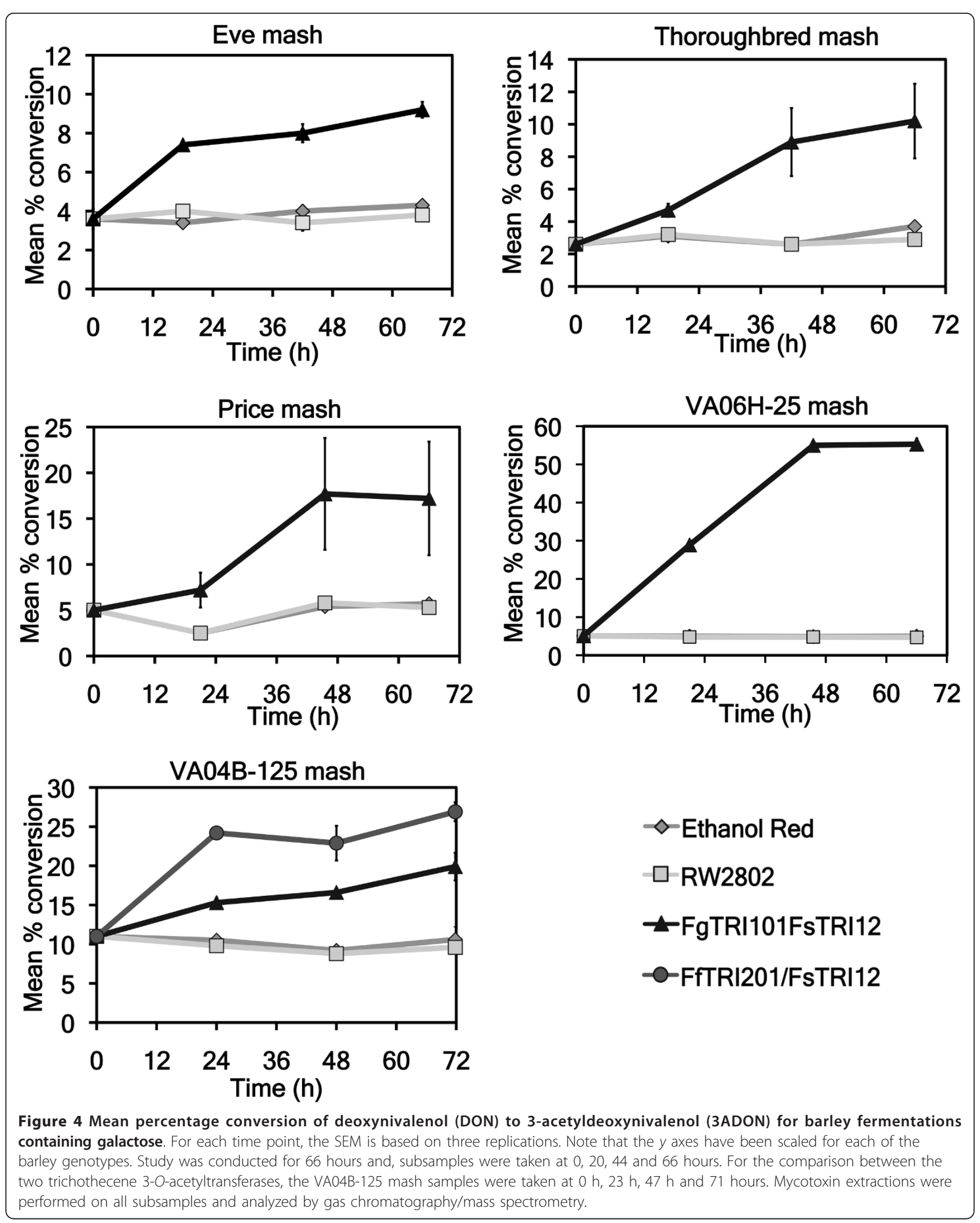




\section{$51 \mathrm{kDa} \quad \begin{array}{rrrrrrr}1 & 2 & 3 & 4 & 5 & 6 & 7\end{array}$}

Figure 5 Western blot of the TRI201 enzyme from Fusarium fujikuroi (FfTRI201) extracted from VA04B-125 mashes. Mash samples weighing $1 \mathrm{~g}$ were collected at the end of fermentation (71 hours), and protein extractions were performed. Mashes containing untransformed RW2802 yeast were used as a negative control. For analysis, $4 \mu \mathrm{l}$ of each extract were loaded onto a $12 \%$ acrylamide-SDS-PAGE gel and run at $150 \mathrm{~V}$ for 1 hour. A protein standard (Precision Plus Protein Dual Color Standard) was used to determine protein size. The western blot was probed with rabbit anti-FSTRI101 primary antibody, and the probe detected with alkaline phosphatase-conjugated anti-rabbit antibody. Lane 1: purified FfTRI201 from Escherichia coli; lane 2: FfTRI201 from mash 1 containing transformed yeast; lane 3 FfTRI201 from mash 2 containing transformed yeast; lane 4: FfTRI201 from mash 3 containing transformed yeast; lane 5: mash 1 containing untransformed RW2802; lane 6: mash 2 containing untransformed RW2802; and lane 7: mash 3 containing untransformed RW2802.

not yield FgTRI101 protein in our western blot analysis, probably because FgTRI101 was below detection levels (data not shown).

\section{Deoxynivalenol/3-acetyldeoxynivalenol in Eve, Price, Thoroughbred and VA06H-25 distillers dried grains with solubles}

The concentration of DON in DDGS was 1.6 to 8.2 times higher than the original ground grain used to prepare the mashes (Table 2). The mass of DON in DDGS samples was lower for all mashes with the transformed RW2802 yeast compared with mashes containing either the untransformed RW2802 or Ethanol Red (Table 3). In the recovered DDGS samples, the mass of DON in DDGS from fermentations with untransformed RW2802 ranged from $178.4 \pm 8.2 \mu \mathrm{g}$ (Eve) to $2496.2 \pm 47.6 \mu \mathrm{g}$ (VA06H-25), whereas it ranged from $157.2 \pm 7.2 \mu \mathrm{g}$ (Eve) to $1098.7 \pm 39.4 \mu \mathrm{g}$ (VA06H-25) from fermentations with transformed RW2802 (Table 3). This reduction was significant for Price and Thoroughbred, the hulled barley cultivars $(P<0.05)$ (Table 3$)$. The DON in DDGS from the hulless line VA06H-25 was significantly lower when derived from mashes with transformed RW2802 than with either untransformed RW2802 or Ethanol Red $P<0.05$ ) (Table 3$)$. The mass of 3ADON was significantly higher in all DDGS samples with transformed RW2802 than in DDGS samples containing untransformed RW2802 or Ethanol Red (Table 3). The largest reduction of DON using transformed yeast, was seen in VA06H-25 DDGS (DON:3ADON ratio of $0.4 \pm$ $0.0)$, and the smallest in Thoroughbred DDGS (2.9 \pm 0.8 ) (Table 3).

\section{Deoxynivalenol/3-acetyldeoxynivalenol in VA04B-125 distillers dried grains with solubles}

In VA04B-125 DDGS, the mean concentration of DON was concentrated 1.8 times compared with the starting ground grain used to prepare the mashes (Table 2). In a comparison between FgTRI101 and FfTRI201 in DDGS derived from VA04B-125 mashes, FfTRI201 produced the greatest reduction in DON. Average DON levels were $1775.1 \pm 36.1 \mu \mathrm{g}$ (FfTRI201), $1845.7 \pm 55.5 \mu \mathrm{g}$ (FgTRI101), $1951.8 \pm 34.4 \mu \mathrm{g}$ (untransformed RW2802) and $2206.2 \pm 8.1 \mu \mathrm{g}$ (Ethanol Red) for the VA04B-125 DDGS (Table 3). DDGS from fermentations with transformed RW2802 had DON levels that were significantly lower than those with Ethanol Red or untransformed RW2802 $(P<0.05)$ (Table 3). The 3ADON mean mass for DDGS with transformed RW2802 was significantly higher than that for DDGS with Ethanol Red or untransformed RW2802 $(P<0.05)$ (Table 3).

\section{Sugar consumption and ethanol yields}

Unlike RW2802, the Ethanol Red yeast consumed galactose (Table 4), leading to significantly higher ethanol concentrations in galactose-containing mashes compared with galactose-free mashes $(P<0.05)$ (Table 4$)$. In galactose-free mashes, ethanol yields ranged from 67.45\% (VA06H-25 with untransformed RW2802) to 91.41\% (VA04B-125 with Ethanol Red) (Table 4),

Table 2 Comparison of deoxynivalenol (DON) concentration in ground grain versus distillers dried grains with solubles (DDGS) from fermentation with Ethanol Red

\begin{tabular}{llll}
\hline Barley line/cultivar & $\begin{array}{l}\text { Ground grain, mean ppm } \pm \\
\text { SEM }\end{array}$ & $\begin{array}{l}\text { Ethanol Red DDGS } \\
\text { (no galactose), mean ppm } \pm \\
\text { SEM }\end{array}$ & Times DON concentrated in DDGS $^{\mathbf{1}}$ \\
\hline VA06H-25 $^{2}$ & $129.5 \pm 14.0$ & $212.9 \pm 3.0$ & 1.6 \\
\hline VA04B-125 $^{3}$ & $118.3 \pm 10.4$ & $207.1 \pm 3.0$ & 1.8 \\
\hline Thoroughbred $^{3}$ & $26.7 \pm 1.3$ & $130.9 \pm 2.4$ & 4.9 \\
\hline Price $^{3}$ & $17.7 \pm 0.5$ & $99.4 \pm 3.5$ & 5.6 \\
\hline Eve $^{2}$ & $2.8 \pm 0.3$ & $23.0 \pm 0.3$ & 8.2 \\
\hline
\end{tabular}

${ }^{1}$ The concentration of DON in the DDGS was 1.6 to 8.2 times that in the original starting grain.

${ }^{2}$ Hulless genotype.

${ }^{3}$ Hulled genotype. 
Table 3 Mass of deoxynivalenol (DON) and 3-acetyldeoxynivalenol (3ADON) in distillers dried grains with solubles (DDGS) derived from mashes amended with galactose

\begin{tabular}{|c|c|c|c|c|}
\hline \multirow[t]{2}{*}{ Barley line/cultivar } & \multirow[t]{2}{*}{ Mycotoxin } & \multicolumn{3}{|c|}{ Mass $^{1}$ of mycotoxin ${ }^{2}$ (mean $\mu \mathrm{g} \pm \mathrm{SEM}$ ) in DDGS with: } \\
\hline & & Ethanol Red & Untransformed RW2802 & Transformed RW2802 \\
\hline \multirow[t]{3}{*}{$\mathrm{VA06H}-25^{3}$} & DON & $1854.6 \pm 55.8^{\mathrm{a}}$ & $2496.2 \pm 47.6^{\mathrm{b}}$ & $1098.7 \pm 39.4^{c}$ \\
\hline & 3ADON & $689.2 \pm 12.4^{\mathrm{a}}$ & $573.8 \pm 27.5^{\mathrm{a}}$ & $2500.2 \pm 40.7^{b}$ \\
\hline & Ratio & $2.7 \pm 0.1^{\mathrm{a}}$ & $4.4 \pm 0.1^{b}$ & $0.4 \pm 0.0^{c}$ \\
\hline \multirow[t]{3}{*}{ VA04B-125 } & DON & $2206.2 \pm 8.1^{\mathrm{a}}$ & $1951.8 \pm 34.4^{\mathrm{b}}$ & $1775.1 \pm 36.1^{c, 5}$ \\
\hline & 3ADON & $233.8 \pm 3.1^{\mathrm{a}}$ & $229.1 \pm 6.1^{\mathrm{a}}$ & $560.1 \pm 10.7^{b, 5}$ \\
\hline & Ratio & $9.4 \pm 0.1^{\mathrm{a}}$ & $8.5 \pm 0.1^{\mathrm{b}}$ & $3.2 \pm 0.1^{c, 5}$ \\
\hline \multirow[t]{3}{*}{ Thoroughbred $^{4}$} & DON & $1100.0 \pm 4.2^{a, b}$ & $1165.7 \pm 55.6^{a}$ & $1001.5 \pm 33.2^{b}$ \\
\hline & 3ADON & $183.4 \pm 1.5^{\mathrm{a}}$ & $130.2 \pm 7.5^{b}$ & $369.0 \pm 7.5^{c}$ \\
\hline & Ratio & $6.0 \pm 0.1^{\mathrm{a}}$ & $9.0 \pm 0.1^{b}$ & $2.9 \pm 0.5^{c}$ \\
\hline \multirow[t]{3}{*}{ Price $^{4}$} & DON & $974.4 \pm 8.1^{a, b}$ & $1090.4 \pm 35.4^{a}$ & $785.2 \pm 86.7^{\mathrm{b}}$ \\
\hline & 3ADON & $123.6 \pm 1.6^{\mathrm{a}}$ & $113.0 \pm 5.2^{\mathrm{a}}$ & $391.0 \pm 123.3^{b}$ \\
\hline & Ratio & $7.9 \pm 0.1^{\mathrm{a}}$ & $9.7 \pm 0.1^{b}$ & $2.5 \pm 0.8^{c}$ \\
\hline \multirow[t]{3}{*}{$\overline{\mathrm{Eve}^{3}}$} & DON & $195.0 \pm 3.7^{\mathrm{a}}$ & $178.4 \pm 8.2^{\mathrm{a}, \mathrm{b}}$ & $157.2 \pm 7.2^{b}$ \\
\hline & 3ADON & $36.2 \pm 2.0^{\mathrm{a}}$ & $22.6 \pm 4.0^{\mathrm{b}}$ & $54.2 \pm 2.1^{c}$ \\
\hline & Ratio & $5.4 \pm 0.4^{\mathrm{a}}$ & $8.7 \pm 2.3^{\mathrm{a}}$ & $2.9 \pm 0.3^{b}$ \\
\hline
\end{tabular}

${ }^{1}$ Mass values of deoxynivalenol not connected by the same letter across rows are significantly different $(P<0.05)$ from each other.

${ }^{2}$ Mycotoxin extraction was performed on $1 \mathrm{~g}$ subsamples of DDGS and analyzed by gas chromatography/mass spectrometry.

${ }^{3}$ Hulless genotype.

${ }^{4}$ Hulled genotype.

${ }^{5}$ DON and 3ADON mass from transformed yeast expressing FfTRI201.

Table 4 Final average ethanol (\% v/v) for mashes with Ethanol Red, untransformed RW2802 and transformed RW2802 yeasts

\begin{tabular}{|c|c|c|c|c|c|c|}
\hline \multirow{2}{*}{$\begin{array}{l}\text { Barley line/ } \\
\text { cultivar }\end{array}$} & \multirow[t]{2}{*}{ Yeast strain } & \multirow{2}{*}{$\begin{array}{l}\text { No galactose } \\
\text { Final ethanol, \% } \\
\text { v/v }\end{array}$} & \multicolumn{2}{|l|}{$10 \%$ Galactose } & \multicolumn{2}{|l|}{ Ethanol yields } \\
\hline & & & $\begin{array}{l}\text { Final ethanol, \% } \\
\text { v/v }\end{array}$ & $\begin{array}{l}\text { Final galactose, \% } \\
\mathbf{v} / \mathbf{v}\end{array}$ & $\begin{array}{l}\text { Without } \\
\text { galactose. \% }\end{array}$ & $\begin{array}{l}\text { With } \\
\text { galactose. \% }\end{array}$ \\
\hline \multirow[t]{3}{*}{$\mathrm{VA06H}-25^{1}$} & Ethanol Red & 9.84 & $14.43^{3}$ & 0.14 & 88.49 & 90.93 \\
\hline & Untransformed RW2802 & 7.50 & 7.40 & 8.37 & 67.45 & 46.63 \\
\hline & $\begin{array}{l}\text { RW2802 transformed with } \\
\text { FgTRI101 }\end{array}$ & 7.51 & 7.57 & 8.03 & 67.54 & 47.70 \\
\hline \multirow[t]{4}{*}{ VA04B-125² } & Ethanol Red & 7.75 & $12.79^{3}$ & 0.44 & 91.41 & 94.74 \\
\hline & Untransformed RW2802 & 6.72 & 6.24 & 8.78 & 79.26 & 46.22 \\
\hline & $\begin{array}{l}\text { RW2802 transformed with } \\
\text { FgTRI101 }\end{array}$ & 7.63 & 7.68 & 8.84 & 90.00 & 56.89 \\
\hline & $\begin{array}{l}\text { RW2802 transformed with } \\
\text { FfTRI201 }\end{array}$ & 7.74 & 7.59 & 8.73 & 91.30 & 56.22 \\
\hline \multirow[t]{3}{*}{ Thoroughbred $^{2}$} & Ethanol Red & 9.43 & $14.26^{3}$ & 0.33 & 83.53 & 88.96 \\
\hline & Untransformed RW2802 & 8.48 & 5.78 & 8.90 & 75.11 & 36.06 \\
\hline & $\begin{array}{l}\text { RW2802 transformed with } \\
\text { FgTRI101 }\end{array}$ & 8.25 & 6.93 & 8.77 & 73.07 & 43.23 \\
\hline \multirow[t]{3}{*}{ Price $^{2}$} & Ethanol Red & 8.27 & $13.24^{3}$ & 0.39 & 87.42 & 92.01 \\
\hline & Untransformed RW2802 & 6.47 & 7.37 & 8.57 & 68.39 & 51.22 \\
\hline & $\begin{array}{l}\text { RW2802 transformed with } \\
\text { FgTRI101 }\end{array}$ & 7.93 & 7.07 & 8.83 & 83.83 & 49.13 \\
\hline \multirow[t]{3}{*}{$\mathrm{Eve}^{1}$} & Ethanol Red & 9.87 & $13.58^{3}$ & 1.72 & 85.60 & 83.62 \\
\hline & Untransformed RW2802 & 9.49 & 6.68 & 9.11 & 82.31 & 41.13 \\
\hline & $\begin{array}{l}\text { RW2802 transformed with } \\
\text { FgTRI101 }\end{array}$ & 9.24 & 6.19 & 8.94 & 80.14 & 38.12 \\
\hline
\end{tabular}


whereas in galactose-containing mashes, ethanol yields ranged from $36.06 \%$ (Thoroughbred with untransformed RW2802) to $94.74 \%$ (VA04B-125 with Ethanol Red) (Table 4). In a comparison between galactose-free mashes, RW2802 produced significantly less ethanol than did Ethanol Red $(P<0.01)$ (Table 4$)$. Since transgene expression only occurred by galactose induction, we examined whether ethanol yields were different between transformed and untransformed RW2802, not accounting for the type of barley. ANOVA showed that ethanol yields were not significantly different between untransformed RW2802 and transformed RW2802 expressing FgTRI101 or FsTRI12 $(P=0.23)$.

\section{Composition of distillers dried grains with solubles}

In a preliminary analysis of DDGS composition, DDGS samples from fermentation with transformed RW2802 yeast were found to be similar to those produced with commercial Ethanol Red yeast (data not shown). Differences in composition occurred only with mashes amended with galactose in which galactose and residual sugars in fermentations were not utilized to completion. RW2802 did not consume galactose during fermentations, causing components of its DDGS to be diluted compared with the Ethanol Red DDGS. For example, the DDGS from VA06H-25 fermented with Ethanol Red in the presence of galactose was composed of $24.43 \%$ protein, $31.27 \%$ neutral detergent fiber (NDF), $1.50 \%$ starch, $0.22 \% \beta$-glucan and $5.06 \%$ crude fat, whereas the DDGS from the same barley line fermented with transformed RW2802 in the presence of galactose contained $13.33 \%$ protein, $14.32 \%$ NDF, $11.23 \%$ starch, $0.14 \% \beta$ glucan and $2.41 \%$ crude fat, (data not shown).

\section{Discussion}

The fungal plant pathogen F. graminearum produces trichothecene mycotoxins that may remain as a contaminant in barley DDGS after fuel ethanol production [30]. New cost-effective and commercially viable methods to reduce mycotoxin contamination in barley DDGS need to be developed and implemented. Our work has a direct relevance to commercial barley ethanol plants in the USA (such as the ethanol plant in Hopewell, Virginia) and in Europe. Preparation of the barley-mash dilutes mycotoxin levels from the ground grain through the addition of DI water or $10 \%$ galactose solution (Figure 2). Mycotoxin levels are then concentrated during the formation of DDGS (Table 2). DON is soluble in water [31], and therefore we would expect a mycotoxin dilution of approximately fourfold in the mash compared with the dry grain (all mashes in this study were $20 \%$ solids). However, not all DON may dissolve in water [32], and therefore increases in ground grain taken from the mash during subsampling may explain the smaller dilutions when the concentration of dry ground grain is compared with levels in the mash at the start of fermentation (Figure 2).

We found large reductions in $\mathrm{DON}$ via conversion (52.4\% to $58.1 \%)$ during fermentation of the hulless barley line VA06H-25, which contained the highest levels of DON in its starting ground grain (Figure 4). This alone demonstrates the tremendous potential for commercial ethanol yeasts to be engineered to express enzymes that modify mycotoxins (such as trichothecene 3-O-acetyltransferases) during fermentation. In a recent study, seven different trichothecene 3-O-acetyltransferases transformed into the yeast strain RW2802 were analyzed for their ability to modify DON into 3ADON during a series of feeding assays [17]; conversion levels ranged from $50.5 \%$ to $100 \%$, depending on the source of the acetyltransferase [17]. In our study, the enzyme FgTRI101 resulted in a 55.3\% mean conversion of DON for the VA06H-25 (hulless barley line), but previous feeding assays with the same enzyme reported a reduction of $92.6 \%$ in yeast cultures [17]. There may be several reasons for the different levels of conversion in our barley ethanol fermentations compared with the previously published feeding assays. It is possible that 'pure' yeast cultures allow higher acetylation rates because of the greater accessibility to DON by the acetyltransferases. The complex matrix of proteins and sugars in barley mashes [33] might impede the ability of the acetyltransferases to interact with DON. The starting concentration of yeast might also play a role in determining DON acetylation rates; the $\mathrm{OD}_{600}$ of yeast inoculum for our hulled line (VA04B-125) was approximately half that of the inoculum for the hulless line (VA06H-25), and might have contributed to the differences in acetylation rates during fermentation between these two lines.

We compared the acetylation levels of two different acetyltransferases (FgTRI101 and FfTRI201) during fermentation, using ground grain from VA04B-125 (hulled barley). Previous work has shown that the enzyme FgTRI101 has a catalytic efficiency towards DON that is 9.2 times greater than that of FfTRI201, but FfTRI201 results in higher DON conversion levels than FgTRI101 likely because of its higher protein expression in yeast [17]. In our study, FfTRI201 converted more DON to 3ADON during fermentation than did FgTRI101 (Figure 4 ), and this was confirmed in the corresponding DDGS (data not shown). Western blot analyses of mashes containing VA04B-125 detected FfTRI201 in all three mashes tested, but FgTRI101 was not detected. Previous studies have reported that FfTRI201 is expressed at higher levels than FgTRI101 in yeast [17], which might explain why the FgTRI101 levels in the VA04B-125 mashes were below the limit of detection in our western blot. 
In our fermentation assays, it is likely that glucose (repression) and galactose (induction) were competing for control of the GAL1 promoter (Figure 1), responsible for FgTRI101 and FfTRI201 expression, and therefore the expression of the acetyltransferases may not have been optimal in the fermentations. Alternative methods to induce protein expression (for example, using inducers other than galactose) may yield larger reductions in DON, especially in grain containing reduced amounts of DON (the substrate). Future studies could use promoters such as CUP1 [34] induced by copper $(100 \mu \mathrm{mol} / 1$ $\left.\mathrm{Cu}^{2+}\right)[35,36]$. The effect of copper on fermentation and DDGS production is unknown; however, addition of copper (30 mg/kg dry mass) to animal feed has been reported to suppress bacterial infections in the gut of swine [37]. Alternatively, for constitutive expression, the phosphoglycerate kinase promoter (PGK1) can be used, and requires no additional components [38].

Previous reports have indicated a threefold increase in the concentration of DON in DDGS relative to starting material [39]. In our study, DON concentrations in DDGS from Ethanol Red fermentations were about 1.6 to 8.2 times higher than in the starting ground grain (Table 2). Unexpectedly, ground grain from resistant genotypes (e.g., Eve), containing a low DON concentration, resulted in the corresponding DDGS having DON levels that were concentrated more than those in DDGS derived from ground grain with high DON levels (e.g., VA06H-25) (Table 2). It is possible that resistant genotypes harbor more masked DON (DON glucosides), through expression of a UDP-glucosyltransferase, [40,41] than do susceptible genotypes (which accumulate high levels of DON), which may be subsequently hydrolyzed by the yeast, causing DON to be released during fermentation [42]. This may help explain our results (Table 2) showing DON concentrating in DDGS relative to the ground grain, but this was not investigated further in the present study, and we were unable to calculate a proper mass balance to compare the masses of DON because of the subsampling of mashes during the course of the fermentation.

The reduction in total solid mass during fermentation (in which glucose is converted to ethanol and carbon dioxide), together with the loss of moisture during drying of the DDGS, increases the concentration of mycotoxins in DDGS. Because the laboratory yeast strain RW2802 does not consume galactose, the components (including DON) of its corresponding DDGS were diluted. Mycotoxin dilutions caused by galactose and other residuals (such as unreacted starch, oligosaccharides, maltose and glucose) remaining because of incomplete fermentation, made calculating the concentration of mycotoxins in the DDGS unreliable, and therefore a mass balance was used (Table 3). Fermentations containing yeast transformed with FgTRI101 or FfTRI201 reduced the mass of DON and increased the mass of 3ADON in all DDGS samples (Table 3). These enzymes are probably inactive in the DDGS because the thermostability values of these enzymes [17] are approximately $15^{\circ} \mathrm{C}$ lower than the temperature at which the DDGS was prepared.

Ethanol yields were greatest in mashes containing Ethanol Red and galactose. This industrial yeast strain was developed for fuel ethanol production and has the unique ability to utilize both galactose and glucose. In most yeast strains, galactose utilization is about onethird that of glucose [43]. The model (laboratory) yeast strain RW2802 does not have the ability to utilize galactose efficiently, thus in our experiments, ethanol yields for RW2802 were significantly lower in the presence of galactose. This is perhaps due to the energy cost on the yeast cells to synthesize enzymes in the Leloir pathway, which make up approximately $5 \%$ of all total cellular enzymes [44]. DON is a known protein synthesis inhibitor [13], but ethanol yields were not affected by DON in our fermentations.

Another approach to reduce DON in DDGS might be to add an exogenous trichothecene 3-O-acetyltransferase preparation to the mash at the start of fermentation. However, the amount of enzyme needed for this approach to be successful is presently unknown. Moreover, the enzyme stability may limit the effectiveness of this strategy [15], and no such preparation is commercially available at this time. Washing the grain [32] before fermentation can be implemented in order to reduce DON levels before mash preparation, in addition to DON modificiation during fermentation. Reduction of mycotoxins in fermentation mashes does not have to be limited to barley. This strategy could also be applied to other fuel ethanol crops such as corn, wheat and sugarcane. For example, in addition to deoxynivalenol, the mycotoxin zearalenone is another common contaminant of corn ethanol co-products [45], and a lactonohydrolase has been shown to decrease levels of zearalenone in spiked cultures of Schizosaccharomyces pombe and E. coli [46].

The EDGE process was developed as a new method for increasing ethanol yields from barley in a commercial setting to advance biofuels made from non-food feedstocks [28]. Employing yeast to express mycotoxindetoxification genes represents a potential strategy to reduce mycotoxin levels in fuel ethanol co-products. However, a number of issues must be addressed before this process is commercialized. First, integrating a transgene into the yeast genome would be preferred over maintaining the gene on a plasmid (which generally requires selective conditions for plasmid propagation). Second, the composition of DDGS in future work using 
transformed yeast would need to be evaluated. Analysis of DDGS composition in this study showed that DDGS produced by transformed yeast was similar to DDGS produced by commercial yeast, except for the change in the concentration of components due to added galactose and residual sugars that were not utilized to completion. Third, the use of a transgenic yeast strain for fuel ethanol production will need to be accepted by policy makers and ethanol production facilities in order to be implemented on a commercial scale.

\section{Conclusions}

When using transformed yeast expressing a trichothecene 3-O-acetyltransferase in small-scale barley fermentations, DON contaminating the ground grain was converted to 3ADON, and thereby the concentration of DON was reduced in DDGS. FfTRI201 resulted in higher acetylation levels than those resulting from FgTRI101 during fermentations in VA04B-125 mashes. In DDGS derived from mashes containing Ethanol Red, DON levels were concentrated 1.6 to 8.2 times compared with those in ground grain, depending on the barley line/cultivar used in the mash, but were reduced when transformed yeast expressing either FgTRI101 or FfTRI201 was used. Mashes with Ethanol Red yeast had higher ethanol yields than mashes with the laboratory yeast strain RW2802. In mashes with galactose, Ethanol Red was able to utilize this sugar for conversion into ethanol, whereas the galactose resulted in reduced ethanol yields with RW2802. To our knowledge, this is the first detailed report of yeast expressing a DON modification enzyme during barley ethanol fermentation, and provides a basis for evaluating novel detoxification enzymes such as DON de-epoxide hydrolases to reduce DON in DDGS in the future.

\footnotetext{
Abbreviations

ANOVA: analysis of variance; 3ADON: 3-acetyldeoxynivalenol; DDGS: ]distillers dried grains with solubles; DI: deionized DON; deoxynivalenol; EDGE: enhanced dry grind enzymatic; FHB: Fusarium head blight; GC/MS: gas chromatography/mass spectrometry; HPLC: high performance liquid chromatography; OD: optical density; ppm: parts per million; rpm: rotations per minute; SDS: sodium dodecyl sulphate; SEM: standard error of the mean; SIM: select ion monitoring; TBST: Tris-buffered saline with Tween; TMSI: trimethylsilylimidazole.
}

\footnotetext{
Acknowledgements

This work was supported primarily by a grant to DGS, CAG and KBH from the Biodesign and Bioprocessing Research Center at Virginia Tech (project number 208-11-110A-012-331-1). Grants to DGS by the Maryland Grains Producers Utilization Board (proposal number 10121612), the Virginia Agricultural Council (proposal number 10183402), the Virginia Small Grains Board (proposal number 10278306) and the United States Wheat and Barley Scab Initiative (proposal number 07185403) also provided support for the work. The conclusions presented here are those of the authors and do not necessarily reflect the views of the United States Department of Agriculture, the Maryland Grain Producers Board, the Virginia Agricultural Council or the Virginia Small Grains Board. Mention of trade names or commercial products in this article is solely for the purpose of providing specific information and
}

does not imply recommendation or endorsement by the USDA, the Maryland Grain Producers Board, the Virginia Agricultural Council or the Virginia Small Grains Board. The USDA is an equal opportunity provider and employer.

\section{Author details}

${ }^{1}$ Virginia Tech, Department of Plant Pathology, Physiology and Weed Science, Blacksburg, VA 24061, Virginia Tech, USA. ²Department of Crop and Soil Environmental Sciences, Blacksburg, VA 24061, USA. ${ }^{3}$ Sustainable Biofuels and Co-Products Research Unit, USDA, ARS, Eastern Regional Research Center, Wyndmoor, PA 19038, USA.

\section{Authors' contributions}

PAK was involved in the design of the experimental work, performed experiments and analytical work involving transgenic yeast, and was the lead writer on the manuscript. JM performed experiments and analytical work on ethanol and sugar quantification, and assisted in editing and writing the manuscript. NPN and $\mathrm{KBH}$ contributed to the design, helped coordinate experimental work, and assisted in editing and writing the manuscript. GB, WSB and CAG were involved in development of the barley lines/cultivars used in this study, and performed all the field work necessary to grow and harvest the barley, and provide the grain. DGS secured funding for the project, and helped design and coordinate the experiments and resulting data analyses. All authors read and approved the final manuscript.

\section{Competing interests}

The authors declare that they have no competing interests.

Received: 1 July 2011 Accepted: 2 September 2011

Published: 2 September 2011

\section{References}

1. Hicks KB, Flores RA, Taylor F, McAloon AJ, Moreau RA, Johnston DB: Hulless barley-a new feedstock for fuel ethanol? 15th EPAC Meeting 2005.

2. Chesapeake Bay Commission: Biofuels and the Bay - Getting it Right to Benefit Farms, Forests, and the Chesapeake: a report of the Chesapeake Bay Commission MD: CBC; 2007

3. Thomason WE, Griffey CA, Alley MM, Phillips SB, Hagood ES, Herbert DA: Growing hulless barley in the mid-Atlantic. Virginia Cooperative Extension 2005.

4. Schill SR: Beefing Up Barley. Ethanol Producer Magazine 2008, 78-84, (.

5. Drapcho CM, Nghiem NP, Walker TH: Biofuels Engineering Process Technology McGraw-Hill; 2008.

6. McChesney D: Nationwide Survey of Distillers Grains for Aflatoxins US Food and Drug Administration; 2006.

7. Ingledew WM: Yeast-Could you base a business on this bug? In Biotechnology in the Feed Industry. Edited by: Lyons TP, Jacques KA. Nottingham, UK: Nottingham University Press; 1999:27-47.

8. Stone CW: Yeast Products in the Feed Industry: A Practical Guide for Feed Professionals Cedar Rapids, IA: Diamond V Mills Inc; 1998.

9. Wu F, Munkvold GP: Mycotoxins in ethanol co-products: modeling economic impacts on the livestock industry and management strategies. J Agric Food Chem 2008, 56:3900-3911.

10. Mielenz JR: Ethanol production from biomass: technology and commercialization status. Curr Opin Microbiol 2001, 4:324-329.

11. Madson PW, Monceaux DA: Fuel ethanol production. The Alcohol Textbook 1995, 227-238.

12. McMullen M, Jones R, Gallenberg D: Scab of wheat and barley: a reemerging disease of devastating impact. Plant Disease 1997, 81.

13. McLaughlin CS, Vaughn MH, Campbell JM, Wei CM, Stafford ME, Hansin BS: Inhibition of protein synthesis by trichothecenes. Mycotoxins in Human and Animal Health 1977, 263-273.

14. Pestka JJ, Smolinski AT: Deoxynivalenol: toxicology and potential effects on humans. J Toxicol Environ Health B Crit Rev 2005, 8:39-69.

15. Garvey GS, McCormick SP, Rayment I: Structural and functional characterization of the TRI101 trichothecene 3-O-acetyltransferase from Fusarium sporotrichioides and Fusarium graminearum: kinetic insights to combating Fusarium head blight. J Biol Chem 2008, 283:1660-1669.

16. Kimura M, Tokai T, Matsumoto G, Fujimura M, Hamamoto H, Yoneyama K, Shibata T, Yamaguchi I: Trichothecene nonproducer Gibberella species 
have both functional and nonfunctional 3-0-acetyltransferase genes. Genetics 2003, 163:677-684.

17. Khatibi PA, Newmister SA, Rayment I, McCormick SP, Alexander NJ, Schmale DG: Bioprospecting for trichothecene 3-o-acetyltransferases in the fungal genus fusarium yields functional enzymes with different abilities to modify the mycotoxin deoxynivalenol. Appl Environ Microbiol 2011, 77:1162-1170.

18. Kimura M, Kaneko I, Komiyama M, Takatsuki A, Koshino H, Yoneyama K, Yamaguchi I: Trichothecene 3-O-acetyltransferase protects both the producing organism and transformed yeast from related mycotoxins. Cloning and characterization of Tri101. J Biol Chem 1998, 273:1654-1661.

19. Muhitch MJ, McCormick SP, Alexander NJ, Hohn TM: Transgenic expression of the TRI101 or PDR5 gene increases resistance of tobacco to the phytotoxic effects of the trichothecene 4,15-diacetoxyscirpenol. Plant Sci 2000, 157:201-207.

20. Ohsato S, Ochiai-Fukuda T, Nishiuchi T, Takahashi-Ando N, Koizumi S, Hamamoto H, Kudo T, Yamaguchi I, Kimura M: Transgenic rice plants expressing trichothecene 3-0-acetyltransferase show resistance to the Fusarium phytotoxin deoxynivalenol. Plant Cell Rep 2007, 26:531-538.

21. Alexander NJ, McCormick SP, Ziegenhorn SL: Phytotoxicity of Selected Trichothecenes using Chlamydomonas reinhardtii as a Model System. Natural Toxins 1999, 265-269.

22. Eriksen GS, Pettersson H, Lundh T: Comparatie cytotoxicity of deoxynivalenol, nivalenol, their acetylated derivatives and de-epoxy metabolites. Food and Chemical Toxicology 2004, 42:619-624.

23. Bondy GS, McCormick SP, Beremand MN, Pestka JJ: Murine lymphocyte proliferation impaired by substituted neosolaniols and calonectrinsFusarium metabolites associated with trichothecene biosynthesis. Toxicon 1991, 29:1107-1113.

24. Thompson WL, Wannemacher RW Jr: Structure-function relationships of 12,13-epoxytrichothecene mycotoxins in cell culture: comparison to whole animal lethality. Toxicon 1986, 24:985-994.

25. Peska JJ: Deoxynivalenol: toxicity, mechanisms and animal health risks. Animal feed science and technology 2007, 137:283-298.

26. Scientific Committee on Food: Opinion on Fusarium toxins. Part 1: Deoxynivalenol (DON). European Commission: Health and Consumer Protection Directorate-General 1999.

27. Bala N, Chimni SS: Recent developments in the asymmetric hydrolytic ring opening of epoxides catalysed by microbial epoxide hydrolase. Tetrahedron: Asymmetry 2010, 21:2879-2898.

28. Nghiem N, Hicks K, Johnston D, Senske G, Kurantz M, Li M, Shetty J, Konieczny-Janda G: Production of ethanol from winter barley by the EDGE (enhanced dry grind enzymatic) process. Biotechnol Biofuels 2010, 3:8.

29. Kushnirov W: Rapid and reliable protein extraction from yeast. Yeast 2000, 16:857-860.

30. Goswami RS, Kistler HC: Heading for disaster: Fusarium graminearum on cereal crops. Molecular Plant Pathology 2004, 5:515-525.

31. Hazel CM, Patel S: Influence of processing on trichothecene levels. Toxicol Lett 2004, 153:51-59.

32. Trenholm HL, Charmley LL, Prelusky DB, Warner RM: Washing procedures using water or sodium carbonate solutions for the decontamination of three cereals contaminated with deoxynivalenol and zearalenone. Journal of Agriculture and Food Chemistry 1992, 40:2147-2151.

33. Vietor RJ, Voragen GJ: Composition of non-starch polysaccharides in wort and spent grain from brewing trials with malt from a good malting quality barley and feed barley. The Journal of The Institute of Brewing 1993, 99:243-248.

34. Macreadie IG, Jagadish MN, Azad AA, Vaughan PR: Versatile cassettes designed for the copper inducible expression of proteins in yeast. Plasmid 1989, 21:147-150.

35. Mascorro-Gallardo JO, Covarrubias AA, Gaxiola R: Construction of a CUP1 promoter-based vector to modulate gene expression in Saccharomyces cerevisiae. Gene 1996, 172:169-170.

36. Mizutani K, Yoshioka S, Mizutani Y, Iwata S, Mikami B: High-throughput construction of expression system using yeast Pichia pastoris, and its application to membrane proteins. Protein expression and purification 2011, 77:1-8.

37. Nicholson FA, Chambers BJ, Williams JR, Unwin RJ: Heavy metal contents of livestock feeds and animal manures in England and Wales. Bioresour Technol 1999, 70:23-31.
38. Lilly M, Lambrechts MG, Pretorius IS: Effect of increased yeast alcohol acetyltransferase activity on flavor profiles of wine and distillates. Applied and environmental microbiology 2000, 66:744-753.

39. Schaafsma AW, Limay-Rios V, Paul DE, Miller JD: Mycotoxins in fuel ethanol co-products derived from maize: a mass balance for deoxynivalenol. Journal of The Science of Food and Agriculture 2009, 89:1574-1580.

40. Berthiller F, Dall'Asta C, Schuhmacher R, Lemmens M, Adam G, Krska R: Masked mycotoxins: determination of a deoxynivalenol glucoside in artificially and naturally contaminated wheat by liquid chromatographytandem mass spectrometry. Journal of agricultural and food chemistry 2005, 53:3421-3425.

41. Poppenberger B, Berthiller F, Lucyshyn D, Sieberer T, Schuhmacher R, Krska R, Kuchler K, Glossl J, Luschnig C, Adam G: Detoxification of the Fusarium mycotoxin deoxynivalenol by a UDP-glucosyltransferase from Arabidopsis thaliana. J Biol Chem 2003, 278:47905-47914.

42. Young JC, Fulcher RG, Hayhoe HJ, Scott MP, Dexter EJ: Effect of milling and baking deoxynivalenol (vomitoxin) content of eastern Canadian wheats. Journal of Agriculture and Food Chemistry 1984, 32:659-664.

43. Ostergaard S, Roca C, Ronnow B, Nielsen J, Olsson L: Physiological studies in aerobic batch cultivations of Saccharomyces cerevisiae strains harboring the MEL1 gene. Biotechnol Bioeng 2000, 68:252-259.

44. Bhat PJ: Galactose Regulon of Yeast Berlin, Germany: Springer; 2008.

45. Schaafsma AW, Limay-Rios V, Paul DE, Miller JD: Mycotoxins in fuel ethanol co-products derived from maize: a mass balance for deoxynivalenol. Science of Food and Agriculture 2009, 89:1574-1580.

46. Takahashi-Ando N, Tokai T, Hamamoto H, Yamaguchi I, Kimura M: Efficient decontamination of zearalenone, the mycotoxin of cereal pathogen, by transgenic yeasts through the expression of a synthetic lactonohydrolase gene. Appl Microbiol Biotechnol 2005, 67:838-844.

doi:10.1186/1754-6834-4-26

Cite this article as: Khatibi et al: Conversion of deoxynivalenol to 3acetyldeoxynivalenol in barley-derived fuel ethanol co-products with yeast expressing trichothecene 3-O-acetyltransferases. Biotechnology for Biofuels 2011 4:26.

\section{Submit your next manuscript to BioMed Central and take full advantage of:}

- Convenient online submission

- Thorough peer review

- No space constraints or color figure charges

- Immediate publication on acceptance

- Inclusion in PubMed, CAS, Scopus and Google Scholar

- Research which is freely available for redistribution 